\title{
Common damages and recommendations for the seismic retrofitting of vernacular dwellings
}

\author{
M. R. Correia \\ CI-ESG, Escola Superior Gallaecia, Portugal \\ H. Varum \\ University of Porto, Porto, Portugal \\ P.B. Lourenço \\ ISISE, University of Minho, Guimarães, Portugal
}

\begin{abstract}
This closure chapter acknowledges the most common retrofitting elements and measures identified in vernacular architecture. It enhances common systematic structural damage and failure mechanisms during earthquakes, relating them with probable causes, and establishing general recommendations to consider in preventive and reactive actions. Also, recommendations for the design and detailing of new construction in prone earthquake areas are advanced.
\end{abstract}

\section{INTRODUCTION}

The earthquake impact in dwelings has been studied since long. The capacity of the structural elements and of the building are crucial for the survival of the dwellings under earthquake demands. The length of the earthquake, its epicentre location in relation to the dwelings, the local soil conditions, and the foundations system have certainly a relevant meaning in the survival of the building stock in earthquake prone regions.

This chapter presents systematic encompassed failures, identified in several of the vernacular dwellings located in seismic areas. It also presents preventive recommendations for new housing, as well as for the strengthening of existent building structures.

\section{STRENGTHENING AND RETROFITTING ELEMENTS}

Based on the research addressed during the Taversism project (Correia, 2002), and throughout the research project 'SEISMIC-V: Vernacular Seismic Culture in Portugal (Correia et al., 2014), the research project team identified several different elements and systems for seismic-retrofitting in vernacular architecture. Following are listed the most common elements and systems, observed during the entailed missions:

\subsection{Strengthening elements.}

Retrofitting elements are commonly applied in vernacular construction, to improve the connection among units in masonry, and/or to improve the capacity of the walls: e.g. horizontal reinforcement inbetween rammed earth layers / adobe masonry / stone masonry; wood connectors used on the interior of walls, Pombalino structural system.

\subsection{Perimeter seismic-resistant elements.}

The perimeter elements aim at locking the built structure, defining a joint behaviour and response of the structural elements, such as walls, floors and roofs (i.e. to develop the so-called "box behaviour"). This ensures the connection and stability of the structural elements in the perimeter of the construction; e.g. buttresses, masonry quality improvement, and other strengthening solutions of the corners, reinforced plinth, and tie-rods.

\subsection{Arches reinforcing elements.}

A combination of arches and vaults arises usually associated with traditional typologies. These are located at the ground floor, of two or more floor buildings, both in urban or peri-urban areas: e.g. arches and vaults on the ground floor; and flat arches (or jack arches) on the top of the openings.

\subsection{Combined reinforcing elements and solutions.}

It comprises, for example, solutions, where structural elements are applied between contiguous buildings or row buildings: e.g. continuous cornice, and counter-arches. 


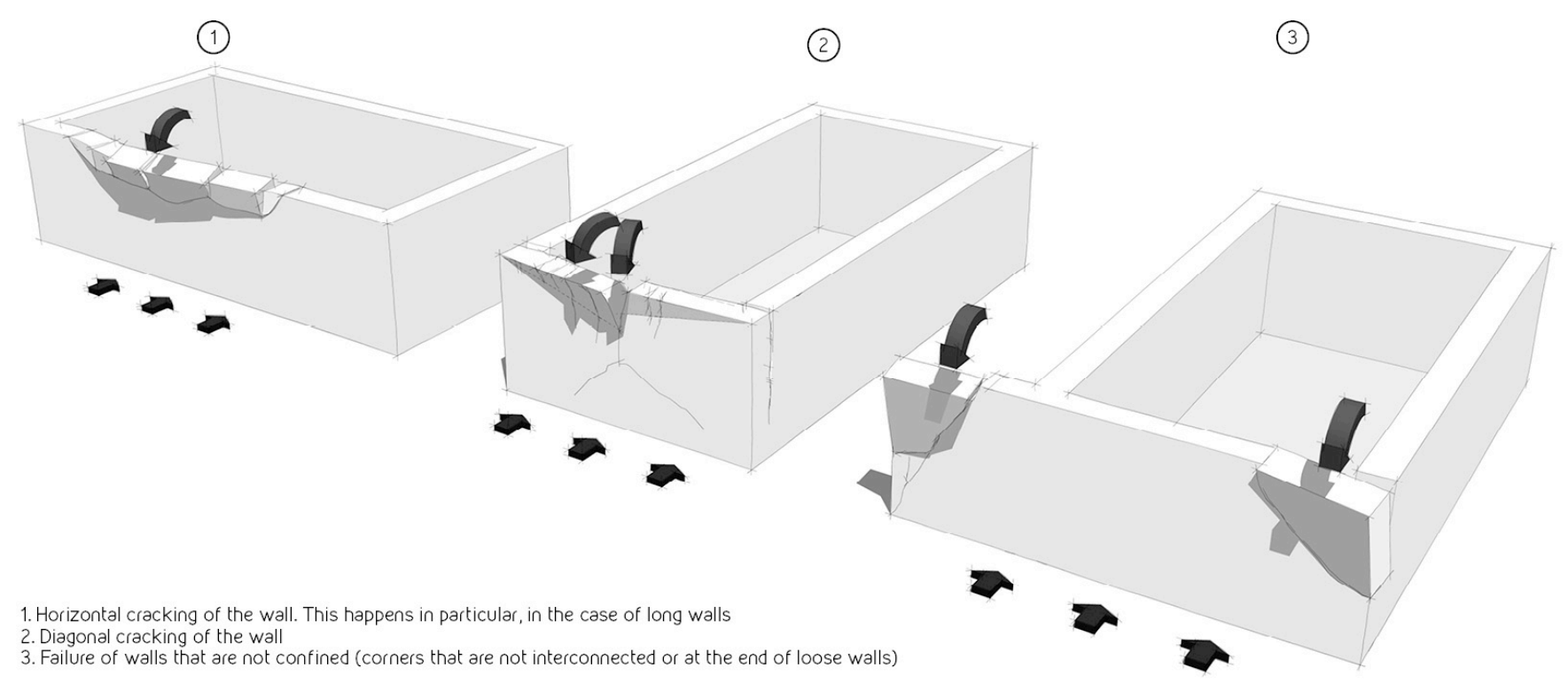

Figure 1. Common out-of-plane failure mechanisms (credits: CI-ESG).

\section{SYSTEMATIC FAILURE AND CAUSES}

To favour the development of seismically safer constructions, recommendations should be addressed on improving and reinforcing protective measures. Attention should also be given to actions that may reduce the seismic impact. Several authors already address these relevant matters, such as Yamín Lacouture et al. (2007), López Trujillo (2014), Prieto Sánchez \& Vargas Neumann (2014), among others.

Following are some of the recommendations that should be considered, when improving the seismic capacity of vernacular architecture and in new construction.

\subsection{Types of failure}

Following, are listed some common types of failure of structural components. The most probable causes, observed in vernacular constructions, when subjected to seismic actions, are also briefly defined:

a) Out-of-plane collapse of exterior walls due to poor connection to the perpendicular walls and to the horizontal structural systems (floors and roof); or due to the masonry poor quality (see Figure 1).

b) Severe in-plane cracking of the walls due to poor shear capacity to resist the horizontal in-plane demands, as a consequence of poor masonry quality, degradation, or large openings.

c) Roof collapse due to the collapse of it supports, due to poor connection with the exterior walls, or due to its heavy mass. d) Floors collapse. Upper floors may collapse due to the collapse of their support system, or due to a weak connection with the exterior walls.

\subsection{Common errors and causes of failure}

Following are listed the common errors and causes of severe damage or failure, verified on one to two floors vernacular buildings, when seismically loaded (see also Figure 2):

a) Heavy roofing systems: Mass concentration on the top of the building may induce high concentrated heavy loads and damages.

b) Poor connection between walls: A weak interlocking in the connection of perpendicular walls may facilitate the out-of-plane of the walls, and decrease the global capacity of the building.

c) Instable gables: Absence or poor connection of the gables to the roof and floor structures.

d) Insufficient strength capacity of the exterior walls: This can be due to thin walls, or to walls with insufficient strength.

e) Low quality of the construction materials or masonry system: Weak units (adobe, stone) of the masonry system; poor mortar, lack of strength of the stone masonry system; masonry without mortar on the vertical joints; uneven compression when building the rammed earth; wicked rammed earth mixture, etc.

f) Improper connection on the building corners: When rammed earth, adobe masonry or stone masonry walls are not tied, or have a poor interlocking, at the building's corners. 


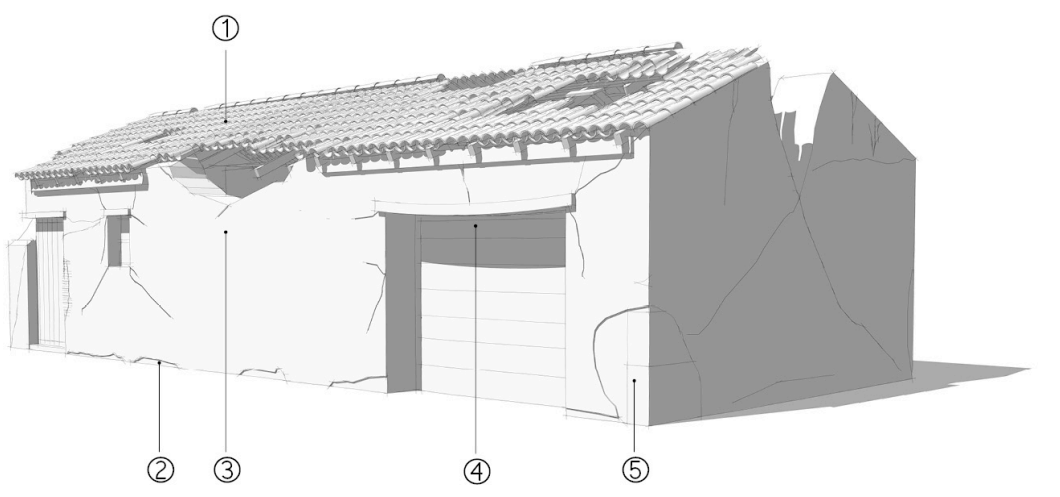

1. Heavy roof / Roof badly retrofitted

2. No plinth or week plinth / No foundations or weak foundations

3. Very large walls and very long walls

4. Too wide openings

5. Incorrect connection on the building corners

Figure 2. Common damages in masonry dwellings due to earthquake demands (credits: CI-ESG).

g) Irregularity on the openings distribution: This may induce a concentration of stresses and demands on the walls, and on the existent openings.

h) Poor or short support of the opening lintels: It may collapse because of the stress concentration on the support, or due to damage of the earthquake demands.

i) Excessive opening dimensions: Too wide door or window openings may lead to stress concentrations and irregular behaviour of the building.

j) Proximity of the openings to building corners: Openings too close to the building corners may lead to a stress concentration in the wall.

k) Windows or doors on the building corners: The presence of openings in the building corner induces a discontinuity between perpendicular walls.

l) Long walls: Long walls, not properly connected to transversal walls and floor/ roof structures tend to exhibit larger out-of-plane deformations.

m) Absence or week foundation system: This may induce excessive deformations on the walls, and in the overall structure.

\section{GENERAL RECOMMENDATIONS}

A standard of general recommendations is addressed in terms of preventive actions and reactive actions, after the construction is erected (even before earthquakes), and/ or criteria for design of new construction.

\subsection{Preventive actions}

First, it is fundamental to address a good construction in terms of materials and building systems. This relies on a suitable connection between elements, but also on materials with adequate properties: good compaction of the rammed earth, good mixture of the adobe earth, stone without salt problems, adequate mortars, etc. a) Foundations: It is fundamental for dwellings to have strong and stable foundations, to ensure a good distribution of the vertical dead load, but also to be able to respond to earthquake lateral demands.

b) Wall plinth: It is relevant to assure a strong and adequate construction of the wall plinth, which guarantees a proper connection of the structure at the ground level.

c) Wall reinforcement: This should be considered between rammed earth horizontal layers or adobe/ stone masonry horizontal joints. These retrofitting measures can be addressed, for example, through the use of internal horizontal wood elements, fired bricklayers, or stone layers, on the horizontal joints of the rammed earth.

d) Walls connection: During the construction, it is important to provide a good connection between interior walls and exterior walls, as well as between exterior walls at the corners. These connections can be improved through the integration of interconnected wood, stone slabs, or brick elements at the corners.

e) Ring beam: Usually applied on the top of the walls and/ or at the floor levels. It promotes an adequate connection of the walls, and improves their out-of-plane capacity.

f) Lintels: Lintels with short support on the door and window openings should be avoided. Lintels should be property connected to the walls.

\subsection{Reactive actions}

a) Foundations: Consolidation or enlargement of foundations, but also careful integration of foundations (Correia \& Merten, 2000), when they do not exist. All these measures will guarantee the adequate transmission of the vertical loads into the soil.

b) Reinforced wall plinth: To be applied externally to the walls, at their base. 
c) Wall reinforcement: As it is difficult to insert horizontal connectors, in-between rammed earth layers or stone masonry joints, masonry reinforce

ment can be considered, when external reinforcing solutions are introduced. For example, in Peru, Colombia and Portugal, several experiences have been made with geo-grids, raffia, etc. (Figueiredo et al., 2007).

d) Buttresses: To be applied in strategic weak points of the building or where out-of-plane may occurs.

e) Tie-rods: To connect opposite walls, at floor or roof levels, to assure their stability to out-of-plane demands.

\subsection{Design criteria}

Some recommendations regarding design criteria and detailing of buildings for prone-earthquake areas, follow herein:

a) Plans should be regular: Regular geometry in plan, as for example symmetrical plans, promotes a regular behaviour and distribution of demanding loads among the structural walls.

b) Regularity in height: Abrupt changes of strength, stiffness or mass in height should be avoided, in order to promote a regular response of the building to seismic demands.

c) Roof structural system and roof coverings should be light: Heavy roofing systems tend to develop high concentrated demands.

d) Openings should not be too wide: Dimensions of the openings should avoid high stress concentration, due to horizontal demands.

e) Openings to close to corners should be avoid$e d$ : Openings should be located far enough from the corner, to avoid stress concentrations.

f) Proper connections between the different ele- ments should be promoted: An adequate connection between walls, roof and walls, and floors and walls, tends to promote lower and better distribution of the demands of the earthquake among the structural elements.

g) Reinforcement elements should be integrated in weak points of the walls: Points, where high demands may be concentrated, should be reinforced with wooden, stone, or brick elements.

h) Accurate constructive details should be provided: Rigorous plans and drawings, including details of the structural elements, connections, etc. should be prepared, to avoid errors in the building construction that may affect its safety.

i) Selection of adequate materials, rigorous construction and monitoring. They all should be considered, so as to guarantee a safe dwelling.

\section{FINAL REMARKS}

From the analysis of vernacular architecture construction details in prone-earthquake areas derived recommendations for the behaviour and performance improvement of vernacular buildings. Simple, though effective measures can be taken at the design phase, such as structural regularity, continuity, etc. Additionally, addressing a consistent reinforcement of the housing can also promote an improved behaviour of the buildings under an earthquake impact.

The seismic safety of existing structures can be improved with these recommendations. Therefore, understanding why systematic failure occurs and how population can address adequate, preventive, or even reactive solutions, can contribute to the safety and survival of local communities, when earthquakes occur.

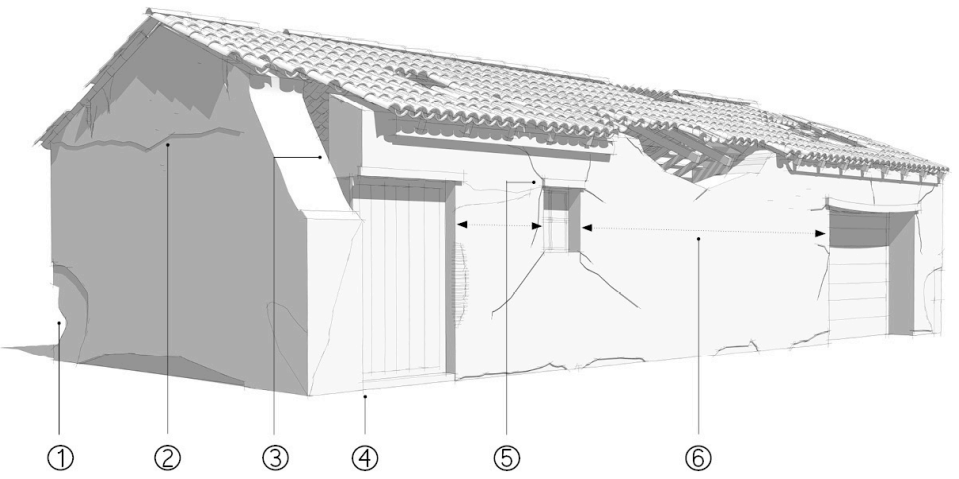

1. Low quality of material - lack of good compression of the rammed earth 2. Lack of horizontal strength between the exterior walls

3. Lack of ties between walls/gables

4. Openings too close to the building corners

5. Poor or short support in the opening lintels

6. Irregularity on the opening distribution

Figure 3. Common damages in masonry dwellings due to earthquake demands (credits: CI-ESG). 


\section{ACKNOWLEDGMENTS}

The authors gratefully acknowledge the support by the Portuguese Science and Technology Foundation (FCT) to the research project 'SEISMIC-V - Vernacular Seismic Culture in Portugal' (PTDC/ATPAQI/ 3934/2012).

\section{REFERENCES}

Correia, M. (2002). Preliminary Report of the Local Seismic Culture in Portugal. TAVERSISM project: La tutela attiva dell'edificato vernacolare nelle zone sismiche: Un'azione polivalente di valorizzazione del patrimonio, riduzione della vulnerabilità, di sviluppo locale. Ravello: UNIVEUR centre.

Correia, M., Carlos, G., Rocha, S., Lourenço, P.B., Vasconçelos, G., \& Varum, H. (2014) Vernacular Seismic Culture in Portugal. In M. Correia, G. Carlos, \& S. Sousa, (Eds). Vernacular Heritage and Earthen Architecture: Contribution to Sustainable Development. Proceedings of CIAV 2013 | $7^{\circ}$ ATP | VerSus. London (UK): CRC Press / Balkema / Taylor \& Francis Group.

Figueiredo, A., Varum, H., Costa, A., Silveira, D., Oliveira, C. (2013). Seismic retrofitting solution of an adobe masonry wall. In Materials and Structures, RILEM, doi 10.1617/s11527-012-9895-1, Vol. 46, N. 1-2, pp.203-219.

Giuliani, H., Citrinovitz, A., Aladro, S. \& Benavidez, H. (1987). Arquitectura sismo-resistente. Un nuevo enfoque para solución integral del problema sísmico. Informes de la Construcción, 38 (387), 64-69.

López Trujillo, O. A. (2014). La importancia de la investigación y reglamentación técnica para la construcción de vivienda con tierra. Projecto de Investigação Seismic-V: Reconhecimento da Cultura Sísmica Local em Portugal in Arquitectura de Tierra: Patrimonio y Sustentabilidade en regiones sísmicas, eds. M. Correia, C. Neves, R. Núñez, El Salvador: Imprimais.

Prieto Sánchez, R. \& Vargas Neumann, J. (eds.) (2014). Fichas para la Reparación de Viviendas de Adobe. Perú: Ministerio de Vivienda, Construcción y Saneamiento.

Yamín Lacouture, L.E., Philips Bernal, C., Reyes Ortiz, J.C., Ruiz Valencia, D. (2007). Estudios de vulnerabilidad sísmica, rehabilitación y refuerzo de casa en adobe y tapia pisada [Seismic vulnerability studies, renovation and reinforcement of houses built with adobe brick and rammed earth]. In APUNTES Vol. 20, N², July - December 2007 (ISBN 1657-9763). Bogotá (Colombia): Pontificia Universidad Javeriana, pp.286-303. 